MIRANDA MAGNOLI, ORIENTADORA. UM PROCESSO DIALÓGICO E COMPREENSIVO DE CONSTRUÇÃO DO CONHECIMENTO

MIRANDA MAGNOLI, ADVISOR.

A DIALOGICAL AND COMPREHENSIVE PROCESS IN THE CONSTRUCTION OF KNOWLEDGE

Catharina P. C. dos Santos Lima

Professora doutora da Faculdade de Arquitetura e Urbanismo da Universidade de São Paulo (FAUUSP).

E-mail:ga2001@uol.com.br 


\section{RESUMO}

A elaboração de um trabalho acadêmico pode ser um processo de aprendizagem extremamente edificante para o educando e seu educador, dependendo das bases em que se estabeleçam essas relações. Este artigo descreve três aspectos considerados por sua autora como fundamentais, para a realização deste trabalho, a partir de suas experiências como orientanda da professora Miranda Magnoli.

\section{Palavras-chave: Educação, área de Paisagismo.}

\section{ABSTRACT}

The development of an academic work can be an extremely constructive learning process for both teacher and pupil. It all depends on the basis on which this relationship is established. The present text describes three aspects considered by its author as essential for the accomplishment of such task, from the perspective of her personal experience as an adviser of professor Miranda Magnoli.

Key words: Education, landscape design field. 


\title{
MIRANDA MAGNOLI, ORIENTADORA. UM PROCESSO DIALÓGICO E COMPREENSIVO DE CONSTRUÇÃO DO CONHECIMENTO
}

\author{
MIRANDA MAGNOLI, ADVISOR. \\ A DIALOGICAL AND COMPREHENSIVE PROCESS IN THE \\ CONSTRUCTION OF KNOWLEDGE
}

Há pouco tempo, em meio a um café, Miranda me contou que dentre as várias atividades de trabalho às quais tem se dedicado, a que lhe dá mais prazer é a de orientar. Não duvido; ao longo de cerca de 30 anos tem contribuído, no âmbito da pós-graduação, para a produção de várias pesquisas, entre dissertações de mestrado e teses de doutorado, e mesmo tendo se afastado formalmente do trabalho acadêmico, continua até hoje dedicando tempo e energia a essa atividade.

Muito haveria a falar sobre sua atuação na pós-graduação; porém, como ao longo desta edição encontra-se publicado um artigo de sua autoria e, por isso mesmo, mais elucidativo e abrangente, sinto-me à vontade para eleger alguns pontos, dentre vários, os quais considero fundantes para o processo de aprendizado mútuo que pode ser o da orientação de um trabalho dessa natureza. Separei, portanto, três aspectos que para mim foram os mais significativos nessa convivência e que, como uma base indelével, têm norteado meu cotidiano de orientação.

\section{Abrindo o Diálogo}

Todos aqueles que passaram pelo processo de elaboração de uma dissertação de mestrado ou de uma tese de doutorado, sabem que a produção de um trabalho científico é um caminho tortuoso envolvendo desde os momentos prazerosos das revelações e conexões inauditas à angústia das edições e enquadramentos; dos insights fantásticos e motivantes à pressão dos prazos; da abertura fascinante do campo à sensação de incompletude. Nesse caminho, o papel do orientador pode ser fundamental para justamente lidar com os aspectos dialéticos inerentes a esse processo; a um só tempo propiciar os movimentos contraditórios de abertura e recorte; mostrar a complexidade do campo provocando, por outro lado, a contribuição disciplinar; perseguir o rigor acadêmico objetivo, abrindo-se à subjetividade das intuições; permitir o vôo alto, mas apontar a base segura de pouso; fornecer a matriz teórica e permitir a expressão criativa e autônoma; permitir o mergulho solitário no objeto, mas também estimular a interlocução com vários sujeitos; educar e ser educado, dentro de uma perspectiva dialógica em que a construção do conhecimento se realiza como um processo no qual contribuem muitas mãos e colaborações de diversos níveis, embora responda pela autoria uma só pessoa. Para o orientando, esse pode ser um processo mais ou menos doloroso, na medida direta de suas competências e habilidades pessoais, mas igualmente do crédito e envolvimento de seu orientador. 
A relação educador-educando, que, por princípio, deveria pautar-se por uma abertura ética à cognoscibilidade, pode ser, inversamente, uma experiência limitadora, impositiva, um exercício nefasto de "educação bancária", tão criticado por Paulo Freire, para quem o educando não pode ser tratado como um simples receptáculo para depósito de informações. Mesmo no âmbito da pós-graduação, em que o caráter da atividade de pesquisa sugere uma experiência libertária e exploratória, não é incomum a filiação estanque a uma linha de pensamento sacramentada pelo orientador, uma espécie de "carimbo" desse último, uma comunicação vertical que se estabelece nos "atendimentos" e está longe do desejo daquele educador, para "quem ensinar não é transferir conhecimento, mas, criar as possibilidades para a sua própria produção ou a sua construção." 1

Nesse sentido, o da construção mais permeável, rizomática e aberta do conhecimento, da educação de duas vias, é que, em meu entender, insere-se o trabalho de orientação da professora Miranda, a qual, inclusive, nunca escondeu o quanto aprendeu com seus orientandos e de como estes estimulam e alimentam, até hoje, sua imaginação.

Penso que essa preocupação em constituir um corpo de conhecimento na área de Paisagismo dentro de uma perspectiva crítica e dialógica, além, é claro, de seu entusiasmo pelo debate e até por uma característica peculiar de sua personalidade (não por acaso sua "oralidade" tem sido muito mais expressiva do que sua produção literária) fizeram com que a professora ampliasse sua contribuição para além de seus orientandos oficiais, mantendo-se não apenas aberta a contribuições informais com outros alunos, mas também incorporando sistematicamente, no desenvolvimento de muitas disciplinas, uma preocupação contínua em abrir o universo das pesquisas individuais, para a discussão e trocas entre as várias percepções e abordagens do trabalho científico em sala de aula, isso significa que solicita aos alunos de uma maneira geral para que apresentem e discutam seus mestrados e doutorados em andamento, como parte do método de trabalho da disciplina, criando uma atmosfera, ora mais descontraída, mas por vezes densa, intensa e controvertida, porém sempre de cooperação. Esse exercício que nega a autoridade e abre-se para a alteridade, encontra em Vygotsky fundamentação pedagógica. Para esse estudioso da educação, muito se ganha nessa interlocução. Vygotsky "chamou de 'zona de desenvolvimento proximal' a distância entre aquilo que o indivíduo é capaz de fazer de forma autônoma (nível de desenvolvimento real) e aquilo que ele realiza em colaboração com os outros elementos do seu grupo social (nível de desenvolvimento potencial)", apostando nessa forma dialógica de aprender².

É bem verdade que nem todos os orientadores originais dessas pesquisas se sentem confortáveis com o que pode ser sentido como uma ingerência sobre seus trabalhos e há também, nesse aspecto, um limiar tênue, por vezes difícil de delimitar por ser um prática aberta; entretanto, aqui temos uma clássica questão de conteúdo e forma; a maneira pela qual esse trabalho tem sido conduzido em vários momentos de reflexão conjunta, na qual é criada uma atmosfera para contribuições coletivas, extrapola totalmente a esfera da individualidade, inserindo-se, eticamente, no espectro mais amplo da formação crítica de um corpo de conhecimento na área de Paisagismo. Quem tenha, porventura, participado abertamente dessa experiência, sabe que riscos e contratempos não apenas fazem parte do processo de formação acadêmica, mas que os ganhos advindos da contribuição de outros olhares sobre seu trabalho suplantam esse desconforto inicial.

Lembro-me de uma ocasião, particularmente especial, na qual vários alunos que cursavam uma disciplina de pós-graduação ministrada pela professora tiveram o prazer nervoso de partilhar suas pesquisas (não importando o estágio em que se encontravam, pois não se tratava de "mostrar serviço", mas de abrir para uma colaboração especial e inesquecível) com o professor Milton Santos, levado à FAU por Miranda. Dispensável recordar que não foi uma contribuição qualquer; tratava-se de um intelectual brilhante, matriz científica de muitos trabalhos instigantes 
e que se prontificou a analisar pesquisas muitas vezes em fase embrionária (em meu caso específico, extremamente naïve) com o maior respeito e atenção. Lembro-me que Miranda forneceu ao professor uma espécie de "mala do saber" com livros de alguns dos principais autores de Paisagismo para ele se familiarizar com o estado da arte de nossa área. Duas semanas depois (quando já havia lido praticamente tudo), o professor Milton Santos retribuiu a gentileza, com uma aula inesquecível na qual reinterpretava criticamente axiomas e postulados, clarificando com sua base teórica todo um campo nebuloso de conceitos fundamentais para nossa área, como, por exemplo, o de natureza e instigando a outras percepções sobre ambiente e paisagem.

Outro momento muito rico foi o da criação de um grupo de trabalho constituído por Miranda e orientandos no final dos anos 1980; esse grupo se reunia periodicamente, na sala do grupo de disciplinas Paisagem e Ambiente, com o propósito de discutir as pesquisas em andamento de cada um de seus componentes. Tínhamos aí mais uma oportunidade de superar dificuldades práticas e consolidar bases conceituais e metodológicas, ora por afinidade ora por contraste; o debate evidenciava, portanto, posições antitéticas, mas era justamente nesses "conflitos" intelectuais que residia a riqueza da dinâmica a contribuir para o crescimento do grupo.

Essa disposição para a troca de idéias motivou-me a criar com os alunos que oriento um grupo de estudos para o debate de inquietações identificadas como semelhantes em suas dissertações e teses. Tem sido um trabalho permeado de muitas dúvidas quanto à sua condução, porém extremamente gratificante como processo de aprendizagem para todos. Um caminho mais aberto é mais trabalhoso e imprevisível e talvez até com ganhos maiores para o processo do que para os produtos, mas significa a disponibilidade para o exercício crítico que transcende a relação orientador-orientando e a contribuição pontual das bancas de exame. Como escreveu Paulo Freire: "... tomar a própria prática de abertura ao outro como objeto da reflexão crítica deveria fazer parte da aventura docente... o sujeito que se abre ao mundo com seu gesto à relação dialógica em que se confirma como inquietação e curiosidade, como inconclusão em permanente movimento na História." ${ }^{3}$

\section{A Base Compreensiva de Trabalho - 1}

Assistimos, na atualidade, a um amplo debate sobre os aspectos perniciosos da excessiva especialização das chamadas ciências parcelares. Encontra-se em xeque a visão reducionista que pretere conexões importantes, inclusive para a clarificação de seu próprio campo. "É hoje reconhecido que a excessiva parcelização e disciplinarização do saber científico faz do cientista um ignorante especializado."

A linearidade de uma visão excessivamente racional, que se pretende objetiva e analítica e a qual ganha fôlego com o surgimento da Revolução Industrial e da ciência moderna tem sido posta em xeque desde a contribuição fundamental da física quântica na primeira metade do século XX e mais recentemente com o paradigma ambiental postulado de forma abrangente e sistêmica, dentro de perspectivas que incluem a dimensão humana das questões antes vistas apenas como "ecológicas". Assim, a questão ambiental problematizada de forma transversal, perpassando de forma indistinta as várias esferas do conhecimento, revolucionou a visão de mundo, chacoalhando redutos científicos, demandando correlações inéditas e novas relações epistemológicas para os que não quisessem incorrer em um anacronismo; como argumenta Leff, "o ambiente não é a ecologia, mas a complexidade do mundo; é um saber sobre as formas de apropriação do mundo e da natureza através das relações de poder que se inscreveram nas formas dominantes de conhecimento. A partir daí, abre-se o caminho que seguimos para delinear, compreender, internalizar e finalmente dar seu lugar - seu nome próprio - à complexidade ambiental" 5 . 
Essa percepção sobre a complexidade ambiental, o entendimento de que processos locais se relacionam com a totalidade pede uma nova visão dos corpos de conhecimento, transversal, interconectada.

A consciência dessa problemática impele-nos aos caminhos interdisciplinares como métodos de enfrentamento da fragmentação das ciências. A entrada em outras epistemes, a transferência de métodos, o reaprender a ver o mundo.

Vale lembrar, entretanto, que a arquitetura jamais compreendeu uma definição estreita de seu campo; em muitas instâncias é denominada ciência social aplicada, e não raro no âmbito de seus cursos de graduação circunscreve-se em universos tão distintos quanto departamentos de artes, departamentos de tecnologia e faculdades de ciências humanas. Em sua essência, portanto, já sugere conexões vitais entre arte, ciência e técnica.

Por sua vez, o campo do Paisagismo é, por sua própria natureza, interdisciplinar. Desde sempre foi preciso entender os ciclos biológicos e as vicissitudes dos reinos vegetal e animal, lidar tecnicamente com materiais inertes, captar as demandas do cliente (seja um indivíduo, grupo social e até a sociedade como um todo), para dar respostas esteticamente satisfatórias que preencham expectativas em projetos, e compreendem ainda custos e planejamento de execução e manutenção. A paisagem, como síntese formal e estética das relações entre a sociedade e seu meio biofísico, sugere um campo abrangente de trabalho. Esse campo tem se complexificado na medida da evolução das sociedades e da própria expansão do quadro de variáveis (cada vez mais diversificadas) que adentram sua episteme.

A consciência dessa problemática foi desde sempre uma constante no trabalho acadêmico da professora Miranda. Coube a ela ampliar o campo do Paisagismo na FAUUSP (trazendo também a contribuição do grupo de Planejamento) em uma perspectiva urbana e ambiental, consolidando o caráter interdisciplinar desse campo. Assim é que área verde se transforma em espaço livre; jardim em paisagem; base física em suporte ecológico e, por sua vez, ecologia em ambiente; o que era especializado ou compartimentalizado ganha em escopo e complexidade, abrindo um campo fantástico de investigação interdisciplinar o qual foi se revelando, sobretudo, por meio das pesquisas que orientou.

É preciso ressaltar, entretanto, que nunca houve por parte de Miranda a intenção de minimizar a importância das áreas verdes, dos jardins, ou dos processos biofísicos. Ao contrário; lembro-me de, em uma certa ocasião, em um fórum de paisagismo, depois de assistir a uma ampla discussão sobre a complexidade do ambiente urbano e de como as escolas de arquitetura deveriam pensar os grande temas e as grandes escalas, Miranda me perguntou por que os professores de Paisagismo não gostavam dos jardins, já que teria sido lá "onde tudo começou!" Essa ironia fina revelava uma preocupação em não deixar que o discurso se sofisticasse de forma preconceituosa, preterindo a pequena e doméstica escala, a esfera privada ou o projeto de plantio como algo menor diante das novas realidades.

Voltando à internalização da complexidade nas docência e pesquisa da área de Paisagismo, cabe a pergunta que talvez resuma parte de nossa inquietação epistemológica desde o final do século XX: como atuar na formação de um ser plural capaz de entender a totalidade, sem que vire um generalista superficial? e, por outro lado, como delimitar recortes teóricos e empíricos para aprofundar temáticas sem reduzir e até perder o contexto de inserção?

Nesse sentido, a orientação de Miranda tem sido muito segura ao insistir na contribuição disciplinar do arquiteto (lato sensu) dentro do campo nebuloso da interdisciplinaridade. Reiteradamente corrige, na condução das pesquisas, os deslizes e desvios de rota provocados pelo encantamento que acomete seus orientandos quando adentram campos tão distintos quanto os da geografia, da filosofia, da antropologia, da botânica, da arte, entre tantos. 
É preciso acrescentar, também, que a professora tem orientado, mais recentemente, "não-arquitetos" os quais trabalham o campo do paisagismo. São trabalhos em andamento que terão, provavelmente, a chance de suscitar provocações inversas.

Dessa forma, Miranda não apenas consolidou posturas e bases para o desenvolvimento desse debate como prossegue inquieta na busca pela afirmação plural da área dentro de uma procura de delineamento das competências específicas.

\section{A Base Compreensiva de Trabalho - 2}

Compreender é uma palavra ambígua; tem ao mesmo tempo as conotações de abranger e entender. No que diz respeito à formação do educando, e dos papéis do educador nesse processo, é, a meu ver, um vocábulo extremamente apropriado. Sugere expandir, abrir frentes, abraçar variadas perspectivas, percebendo as potencialidades, mas também as limitações e a maturidade do educando no enfrentamento conceitual e metodológico proposto. A prática pedagógica progressista e libertária formulada por Paulo Freire, em sua luta contra o modelo pragmático de educador, enseja a construção do conhecimento a partir da troca de saberes, experiências, vivências, e a generosidade para acolher, compreender, aceitar. Nada disso pode ser feito sem uma boa dose de afetividade, conceito temido nos círculos acadêmicos, científicos, pela possibilidade de contaminar, confundir a objetividade dos processos e produtos. Finalizo este texto, fazendo esta provocação, mas para não correr riscos faço minhas as palavras de Paulo Freire:

"E o que dizer, mas sobretudo que esperar de mim, se, como professor, não me acho tomado por este outro saber, o de que preciso estar aberto ao gosto de querer bem, às vezes a coragem de querer bem aos educandos e à própria prática educativa de que participo. Esta abertura ao querer bem... significa, de fato que a afetividade não me assusta, que não tenho medo de expressá-la. Significa esta abertura ao querer bem a maneira que tenho de autenticamente selar o meu compromisso com os educandos, numa prática específica do ser humano. Na verdade, preciso descartar como falsa a separação radical entre seriedade docente e afetividade. Não é certo, sobretudo do ponto de vista democrático, que serei tão melhor professor quanto mais severo, mais frio, mais distante e 'cinzento' me ponha nas relações com os alunos, no trato dos objetos cognoscíveis que devo ensinar. A afetividade não se acha excluída da cognoscibilidade. O que não posso obviamente permitir é que minha afetividade interfira no cumprimento ético do meu dever de professor no exercício de minha autoridade. Não posso condicionar a avaliação do trabalho escolar de um aluno ao maior ou menor querer bem que tenha por ele... é preciso, por outro lado, reinsistir em que não se pense que a prática educativa vivida com afetividade e alegria, prescinda da formação científica séria e da clareza política dos educadores ou educadoras. A prática educativa é tudo isso: afetividade, alegria, capacidade científica, domínio técnico a serviço da mudança... como prática estritamente humana jamais pude entender a educação como uma prática fria, sem alma, em que os sentimentos e as emoções, os desejos e os sonhos devessem ser reprimidos por uma espécie de ditadura reacionalista. Nem tampouco jamais compreendi a prática educativa como uma experiência a que faltasse o rigor em que se gera a necessária disciplina intelectual." 6

Em tempo, quando cheguei por aqui e nada entendi... foi a professora quem me guiou da "curiosidade ingênua" à "curiosidade epistemológica", no sentido freireano mais legítimo, criando essa base compreensiva de trabalho para que, por meio da paisagem, eu pudesse ver o mundo. 


\section{Notas}

(1) FREIRE, Paulo, 2004.

(2) VYGOTSKY, Lev S. apud REGO, Teresa Cristina, 2006.

(3) FREIRE, Paulo, 2004.

(4) LEFF, Enrique, 2000.

(5) Idem

(6) Freire, Paulo, 2004.

\section{Bibliografia}

FREIRE, Paulo. A pedagogia da autonomia. São Paulo: Ed. Paz e Terra, 2004.

LEFF, Enrique. Epistemologia ambiental. São Paulo: Cortez, 2000.

VYGOTSKY, Lev Semenovich. Uma educação dialética. In: Coleção Memória da Pedagogia, São Paulo, n. 2, 2006. 